\title{
Quantifying Intra-Arterial Verapamil Response as a Diagnostic Tool for Reversible Cerebral Vasoconstriction Syndrome
}

(D).M. Sequeiros, (D).A. Roa, (D) R.P. Sabotin, (D). Dandapat, (D). Ortega-Gutierrez, (D)E.C. Leira, (D)C.P. Derdeyn, (D) G. Bathla,

(DD.M. Hasan, and DE.A. Samaniego

\begin{abstract}
BACKGROUND AND PURPOSE: There is mounting evidence supporting the benefit of intra-arterial administration of vasodilators in diagnosing reversible cerebral vasoconstriction syndrome. We prospectively quantified the degree of luminal diameter dilation after intra-arterial administration of verapamil and its accuracy in diagnosing reversible cerebral vasoconstriction syndrome.
\end{abstract}

MATERIALS AND METHODS: Patients suspected of having intracranial arteriopathy on noninvasive imaging and referred for digital subtraction angiography were enrolled in a prospective registry. Intra-arterial verapamil was administered in vascular territories with segmental irregularities. The caliber difference (Caliber post $_{-}$Caliber $_{\text {pre) }}$ and the proportion of caliber change ([(Caliber post $^{-}$ Caliber ${ }_{\text {pre }}$ /Caliber pre $] \times 100 \%$ ) were used to determine the response to verapamil. The diagnosis of reversible cerebral vasoconstriction syndrome was made on the basis of clinical and imaging features at a follow-up appointment, independent of the reversibility of verapamil. Receiver operating characteristic curve analysis was performed to determine the best threshold.

RESULTS: Twenty-six patients were included, and 9 (34.6\%) were diagnosed with reversible cerebral vasoconstriction syndrome. A total of 213 vascular segments were assessed on diagnostic angiography. Every patient with a final diagnosis of reversible cerebral vasoconstriction syndrome responded to intra-arterial verapamil. The maximal proportion of change $(P<.001)$, mean proportion of change $(P=.002)$, maximal caliber difference $(P=.004)$, and mean caliber difference $(P=.001)$ were statistically different between patients with reversible cerebral vasoconstriction syndrome and other vasculopathies. A maximal proportion of change $\geq 32 \%$ showed a sensitivity of $100 \%$ and a specificity of $88.2 \%$ to detect reversible cerebral vasoconstriction syndrome (area under the curve $=0.951$ ). The Reversible Cerebral Vasoconstriction Syndrome-2 score of $\geq 5$ points achieved a lower area under the curve (0.908), with a sensitivity of $77.8 \%$ and a specificity of $94.1 \%$.

CONCLUSIONS: Objective measurement of the change in the arterial calibers after intra-arterial verapamil is accurate in distinguishing reversible cerebral vasoconstriction syndrome from other vasculopathies. A proportion of change $\geq 32 \%$ has the best diagnostic performance.

ABBREVIATIONS: $A U C=$ area under the curve; $C D=$ caliber difference; $I A=$ intra-arterial; $I C A D=$ intracranial atherosclerotic disease; $D S A=$ digital subtraction angiography; PACNS = primary angiitis of the central nervous system; PC = proportion of change; RCVS = reversible cerebral vasoconstriction syndrome; $\mathrm{ROC}=$ receiver operating characteristic; $\mathrm{TCH}=$ thunderclap headache

$\mathbf{R}$ eversible cerebral vasoconstriction syndrome (RCVS) comprises a group of disorders characterized by prolonged-butreversible vasoconstriction of the cerebral arteries. It is usually characterized by self-limited and reversible multifocal narrowing, which is associated with acute-onset, severe, recurrent headaches with or without additional neurologic deficits. ${ }^{1}$ Vasoconstriction often involves distal cerebral arteries, develops in the first

Received May 29, 2020; accepted after revision July 4

From the Departments of Neurology (J.M.S., J.A.R., R.P.S., S.D., S.O.-G., E.C.L., E.A.S.), Neurosurgery (J.A.R., S.O.-G., D.M.H., E.A.S.), and Radiology (S.O.-G., C.P.D., G.B., E.A.S.), University of lowa Hospitals and Clinics, lowa City, lowa.

This work was supported by the 2019 Brain Aneurysm Research Grant from The Bee Foundation and by a Pilot Research Grant from the Society of Vascular and Interventional Neurology, both granted to Edgar Samaniego.
4-5 days after symptom onset, and persists for $>3$ weeks. $^{2}$ Due to the lack of specific criteria, the presumptive diagnosis needs to be confirmed with reversibility of angiographic abnormalities within 12 weeks of clinical onset. ${ }^{3,4}$ Other intracranial stenotic arteriopathies such as primary angiitis of the central nervous system (PACNS), Moyamoya disease, or intracranial atherosclerotic disease (ICAD) present with similar findings on initial noninvasive

Please address correspondence to Edgar A. Samaniego, MD, MS, 200 Hawkins Dr, lowa City, IA 52246; e-mail: edgarsama@gmail.com; @esamaniego

Indicates article with supplemental on-line tables.

Indicates article with supplemental on-line photos.

http://dx.doi.org/10.3174/ajnr.A6772

AJNR Am J Neuroradiol 41:1869-75 Oct 2020 www.ajnr.org 
imaging. ${ }^{5,6}$ Distinguishing these conditions early in their course is crucial because treatment options are different, have potential adverse effects, and may affect clinical outcomes. ${ }^{7}$ Clinical and radiologic differences between RCVS and PACNS have been described ${ }^{8}$ however, a prompt and accurate diagnosis remains challenging in patients with atypical presentation. ${ }^{9}$

Calcium channel blockers have been used to challenge vasoconstrictive changes in patients with suspected RCVS. ${ }^{10-18}$ However, other arteriopathies may have reversible changes with time, and it is unclear whether calcium channel blockers can be used reliably to diagnose RCVS. We evaluated the degree of response to intra-arterial (IA) infusion of verapamil as a diagnostic tool in distinguishing RCVS from other intracranial vasculopathies.

\section{MATERIALS AND METHODS}

After institutional review board approval, patients were enrolled in a prospective registry for patients with intracranial vasculopathy between September 2017 and January 2020. As part of the clinical protocol at our institution, patients with possible underlying vasculopathy are routinely referred for digital subtraction angiography (DSA). IA verapamil challenge was performed as part of the diagnostic DSA. Demographic, clinical, laboratory, and radiologic data were collected from electronic medical charts at discharge and last follow-up.

\section{Diagnosis of RCVS}

The final diagnosis of RCVS was adjudicated after the last outpatient follow-up and was based on the criteria proposed by Calabrese et al. ${ }^{1}$ The adjudication was independent of the reversibility of vascular changes after IA verapamil. The criteria proposed by Calabrese et al include the following: 1) severe, acute headache with or without neurologic signs or symptoms, 2) normal or nearnormal CSF analysis findings (protein level $<80 \mathrm{mg} \%$; leukocyte count $<10 \mathrm{~mm}^{3}$; and normal glucose level), 3) angiography documenting multifocal segmental cerebral artery vasoconstriction, 4) no evidence of aneurysmal SAH, and 5) reversibility of angiographic abnormalities within 12 weeks after onset.

\section{IA Verapamil Challenge}

DSA was performed with selective catheterization of the internal carotid and vertebral arteries. Subtracted images were reviewed, and if there was evidence of irregularities suggestive of an underlying vasculopathy, $5 \mathrm{mg}$ of IA verapamil was slowly administered for 10 minutes in the most affected vascular territory. Blood pressure was closely monitored to avoid a drop of $>5 \mathrm{~mm} \mathrm{Hg}$ in mean arterial pressure during the IA administration of verapamil. If the patient experienced any substantial drop in blood pressure, the IA infusion was stopped and resumed only once the blood pressure was back to baseline. A total of $5 \mathrm{mg}$ of verapamil was diluted in saline to a final concentration of $0.5 \mathrm{mg} / \mathrm{mL}$ and manually infused at a continuous rate of $1 \mathrm{~mL} / \mathrm{min}$ through the side port of a 3-way valve connected to the diagnostic catheter and to a continuous heparinized saline infusion. A repeat angiogram of the same vascular territory was obtained 10 minutes following the IA administration of verapamil.

\section{Radiologic Assessment}

Qualitative and quantitative assessment was performed using PACS software. To achieve accurate measurements before and after verapamil injections, we used the same projection angle, source-to-object distance ( $\mathrm{x}$-ray tube to patient), and patient-todetector distance in both angiograms. We used $2 \times$ magnification for imaging assessment in all cases. The qualitative assessment of reversibility was performed blindly, comparing pre- and post-verapamil angiograms that were provided by the Department of Radiology without any identifiers (name, time, or order). Anterior-posterior, lateral, and oblique projections were evaluated by 2 experienced neurointerventionalists (E.A.S. and S.D.). Both reviewers were blinded to clinical data and did not know the sequence of pre- and post-verapamil angiograms. Score sheets to determine arterial involvement, vascular territory affected, and morphologic changes between both angiograms were collected (On-line Figs 1 and 2). Vascular territories were divided as follows: 1) proximal branches: A1, M1, P1, vertebral artery, and basilar artery; 2) middle branches: A2, M2, P2, superior cerebellar artery, anterior-inferior cerebellar artery, posterior-inferior cerebellar artery; and 3) distal branches: A3, M3-M4, P3, and any other more distal branch. Morphologic changes were reported as the following: 1) concentric, smooth tapering ("sausaging”); 2) eccentric narrowing, irregular/notched; and 3) segmental dilation, using the same description by Singhal et al. ${ }^{8}$ The response to IA verapamil was graded as a dichotomous variable (yes/no).

A quantitative assessment was performed by measuring the caliber of different arterial segments on pre- and post-verapamil angiograms. ${ }^{19}$ The diameter of proximal, middle, and distal arterial branches was measured in millimeters. For each patient, the intracranial artery located in the most affected vascular territory was identified; this artery usually showed multiple irregularities suggestive of a vasculopathy process. The area of maximal narrowing of each vascular segment was measured on pre- and postverapamil angiograms. After visual inspection, areas that appeared more stenotic in each segment were measured; the reviewer registered only the shortest caliber in each segment and used the same area for assessing the patient's second angiogram. Measurements were performed by the same reviewers in a different session at least 4 weeks from the initial subjective assessment. Again, reviewers were blinded to clinical data and the order of the angiograms. Two objective measurements of change (reversibility) were statistically tested as predictors of RCVS:

1) Caliber Difference $=$ Caliber $_{\text {post }}-$ Caliber $_{\text {pre }}$

2) Proportion of Change

$$
=\left[\frac{\left(\text { Caliber }_{\text {post }}-\text { Caliber }_{\text {pre }}\right)}{\text { Caliber }_{\text {pre }}}\right] \times 100 \% \text {. }
$$

For each equation, mean and maximal values were used (a total of 4 measurements per arterial segment). Changes in diameter were analyzed with a receiver operating characteristic (ROC) curve to determine the best threshold in diagnosing RCVS.

The performance of the RCVS-2 score was compared with the objective radiologic determination of reversibility. The RCVS- 2 
Table 1: Baseline, clinical course, and work-up among patients with and without RCVS

\begin{tabular}{|c|c|c|c|}
\hline Variable & $\operatorname{RCVS}(n=9)$ & No RCVS $(n=17)$ & $P^{a}$ \\
\hline Age (mean) (yr) & 44.9 & 55.7 & .06 \\
\hline Women (\%) & $8(88.9)$ & $10(58.8)$ & .19 \\
\hline \multicolumn{4}{|l|}{ Race } \\
\hline White (\%) & $8(88.9)$ & $12(70.6)$ & .39 \\
\hline African American (\%) & $1(11.1)$ & $2(11.8)$ & \\
\hline Other (\%) & $0(0)$ & $3(17.7)$ & \\
\hline \multicolumn{4}{|l|}{ Medical history } \\
\hline Migraine (\%) & $4(44.4)$ & $0(0)$ & .008 \\
\hline Depression/anxiety (\%) & $8(88.9)$ & $3(17.6)$ & .001 \\
\hline Hypertension (\%) & $2(22.2)$ & $14(82.4)$ & .009 \\
\hline Trigger/associated condition & $7(77.8)$ & $2(11.8)$ & .002 \\
\hline \multicolumn{4}{|l|}{ Vasoconstrictive drugs } \\
\hline SSRI (\%) & $6(66.7)$ & $1(5.9)$ & .002 \\
\hline Illicit drugs (\%) & $0(0)$ & $1(5.9)$ & .65 \\
\hline Postpartum (\%) & $2(22.2)$ & $0(0)$ & .11 \\
\hline \multicolumn{4}{|l|}{ Clinical presentation } \\
\hline Thunderclap headache (\%) & $5(55.6)$ & $1(5.9)$ & .01 \\
\hline Other headaches (\%) & $2(22.2)$ & $5(29.4)$ & .54 \\
\hline \multicolumn{4}{|l|}{ Focal neurologic signs } \\
\hline Hemiparesis/aphasia (\%) & $5(55.6)$ & $10(58.8)$ & .99 \\
\hline Visual symptoms (\%) & $3(33.3)$ & $1(5.9)$ & .10 \\
\hline Seizures (\%) & $2(22.0)$ & $1(5.9)$ & .27 \\
\hline \multicolumn{4}{|l|}{ Diagnostic work-up } \\
\hline ESR (mean) $(\mathrm{mm} / \mathrm{h})$ & 22.5 & 43.9 & .31 \\
\hline CRP (mean) (mg/L) & 3.0 & 1.9 & .61 \\
\hline Normal $\mathrm{CSF}^{\mathrm{b}}(\%)$ & $2 / 5(40.0)$ & $4 / 9(44.4)$ & .99 \\
\hline Brain biopsy (\%) & $1(11.1)$ & $1(5.9)$ & .58 \\
\hline \multicolumn{4}{|l|}{ Abnormal neuroimaging findings (\%) } \\
\hline Infarct (\%) & $3(33.3)$ & $13(76.5)$ & .046 \\
\hline Multiple (\%) & $2 / 3(66.7)$ & $12 / 13(92.3)$ & .35 \\
\hline Borderzone territory (\%) & $2 / 3(66.7)$ & $1 / 13(7.7)$ & .08 \\
\hline $\mathrm{IPH}(\%)$ & $0(0)$ & $4(23.5)$ & .26 \\
\hline SAH in convexity (\%) & $5(55.6)$ & $2(11.8)$ & .03 \\
\hline \multicolumn{4}{|l|}{ CTA/MRA with vasculopathy } \\
\hline $\mathrm{CTA}[n=14]^{\mathrm{C}}(\%)$ & $2 / 5(40)$ & $5 / 9(55.6)$ & .99 \\
\hline $\operatorname{MRA}[n=16]^{c}(\%)$ & $2 / 6(33.3)$ & $10 / 10(100)$ & .008 \\
\hline $\begin{array}{l}\text { Patients with intracranial vasculopathy } \\
\text { on DSA not detected by CTA and/or } \\
\text { MRA }(n=26)(\%)\end{array}$ & $6 / 9(66.7)$ & $3 / 17(17.6)$ & .028 \\
\hline RCVS- 2 score of $\geq 5$ & $5(55.6)$ & $1(5.9)$ & .01 \\
\hline
\end{tabular}

Note:-CRP indicates C-reactive protein; ESR, erythrocyte sedimentation rate; IPH, intraparenchymal hemorrhage; SSRI, selective serotonin reuptake inhibitor.

${ }^{a} P$ value calculated using a $t$ test, $\chi^{2}$ test, or Fisher test as appropriate.

${ }^{b}$ Normal CSF if $<5$ cells and $<50 \mathrm{mg} / \mathrm{dL}$.

${ }^{c}$ Number of examinations performed including both groups.

normality using the Shapiro-Wilk method. For normally distributed variables, Student $t$ tests were used to compare means. For nonparametric variables, Mann-Whitney $U$ tests were used to compare the medians between the size groups. For categoric values, $\chi^{2}$ or Fisher tests were applied as appropriate. An ROC analysis using the Youden index was performed to establish the best cutoffs for measurements of reversibility (CD and PC) to diagnose RCVS. The RCVS-2 score was also compared with our objective assessments of reversibility in pre- and post-verapamil angiograms using the DeLong test. A 2 -sided $P$ value $<.05$ was considered significant. All statistical analyses were performed with SPSS Statistics 25.0 (IBM).

\section{RESULTS}

Twenty-six patients with intracranial vasculopathy and suspected RCVS were included in the study. Nine patients had a confirmed clinical diagnosis of RCVS (34.6\%); 8 with ICAD; 7 with undetermined intracranial vasculopathy; and 2 with PACNS (Table 1).

\section{Qualitative Assessment}

Both reviewers reported an angiographic response to IA verapamil in $88.9 \%(8 / 9)$ of patients in the RCVS group versus $41.2 \%$ (reviewer 1) and $47.1 \%$ (reviewer 2) in the no-RCVS group (On-line Table 1). The Cohen $\kappa$ analysis demonstrated poor intraobserver agreement to subjectively detect RCVS by comparing pre- and post-ve-

score is a semiquantitative scoring system developed as a bedside diagnostic algorithm. This grading system adjudicates points to different categories as follows: single or recurrent thunderclap headache $(\mathrm{TCH})=+5$ points, involvement of the intracranial carotid artery $=-2$ points, a vasoconstrictive trigger $=+3$ points, female sex $=+1$ point, and the presence of subarachnoid hemorrhage $=+1$ point. A score $\geq 5$ has a high sensitivity and specificity in diagnosing RCVS. ${ }^{9}$

\section{Statistical Analysis}

Continuous variables are presented as mean $\pm \mathrm{SD}$, and categoric variables are presented as frequency and percentage. Distributions of values for mean and maximal measurements of reversibility (caliber difference $[\mathrm{CD}]$ and proportion of change $[\mathrm{PC}]$ ) were tested for rapamil DSAs (reviewer 1: $\kappa=0.41, P=.019$; reviewer 2: $\kappa=$ $0.35, P=.037)$. Also, the interrater reliability to detect overall vascular changes was very poor $(\kappa=0.28, P=.149)$.

\section{Quantitative Assessment}

Two hundred thirteen vascular segments were assessed on DSA, and $87(40.5 \%)$ had post-IA verapamil changes. The statistical analysis showed significant differences in all measurements of reversibility for patients with RCVS, including maximal PC $(P<.001)$, mean PC $(P=.002)$, maximal CD $(P=.004)$, and mean CD $(P=.001)$ compared with patients without RCVS (Table 2 and On-line Table 2). The Cohen $\kappa$ analysis demonstrated substantial interobserver agreement for objective vessel diameter measurements $(\kappa=0.86)$. 


\section{CD and PC as Predictors of RCVS}

ROC curve analysis was performed to establish the best PC and CD thresholds in diagnosing RCVS (Fig 1). Maximal PC $\geq 32 \%$ had a sensitivity of $100 \%$ and a specificity of $88.2 \%$ to detect RCVS, with an excellent area under the curve (AUC) of 0.951 . However, an RCVS- 2 score of $\geq 5$ points had a sensitivity of $77.8 \%$ and a specificity of $94.1 \%$, achieving a nonstatistically significant lower AUC in the analysis $(0.908)(P=.47)$. Mean $\mathrm{PC}$ and mean $\mathrm{CD}$ performed similarly in the analysis (AUC $=0.886$ and 0.882 , respectively), whereas maximal CD performed the worst $(\mathrm{AUC}=0.840)($ Table 3$)$.

\section{DISCUSSION}

Reversibility of intracranial vasoconstriction is the key to diagnosing RCVS. In this study, the objective assessment of caliber changes

Table 2: Reversibility measurements among patients with and without RCVS

\begin{tabular}{lccc}
\hline Reversibility Measurement $^{\mathrm{a}}$ & RCVS $(\boldsymbol{n}=9)$ & No RCVS $(\boldsymbol{n}=17)$ & $\boldsymbol{P}$ Value $^{\mathrm{b}}$ \\
\hline Maximal PC (\%) & $50.6 \pm 13.6$ & $21.7 \pm 12.5$ & $<.001$ \\
Mean PC (\%) & $20.4 \pm 9.8$ & $6.2 \pm 6.0$ & .002 \\
Maximal CD (mm) & $0.54 \pm 0.27$ & $0.25 \pm 0.17$ & .004 \\
Mean CD (mm) & $0.23 \pm 0.13$ & $0.07 \pm 0.08$ & .001 \\
\hline
\end{tabular}

${ }^{a}$ Reversibility measurements shown as mean \pm SD.

${ }^{\mathrm{b}} \mathrm{P}$ value was calculated using the Mann-Whitney $U$ test, given a nonparametric distribution of data.

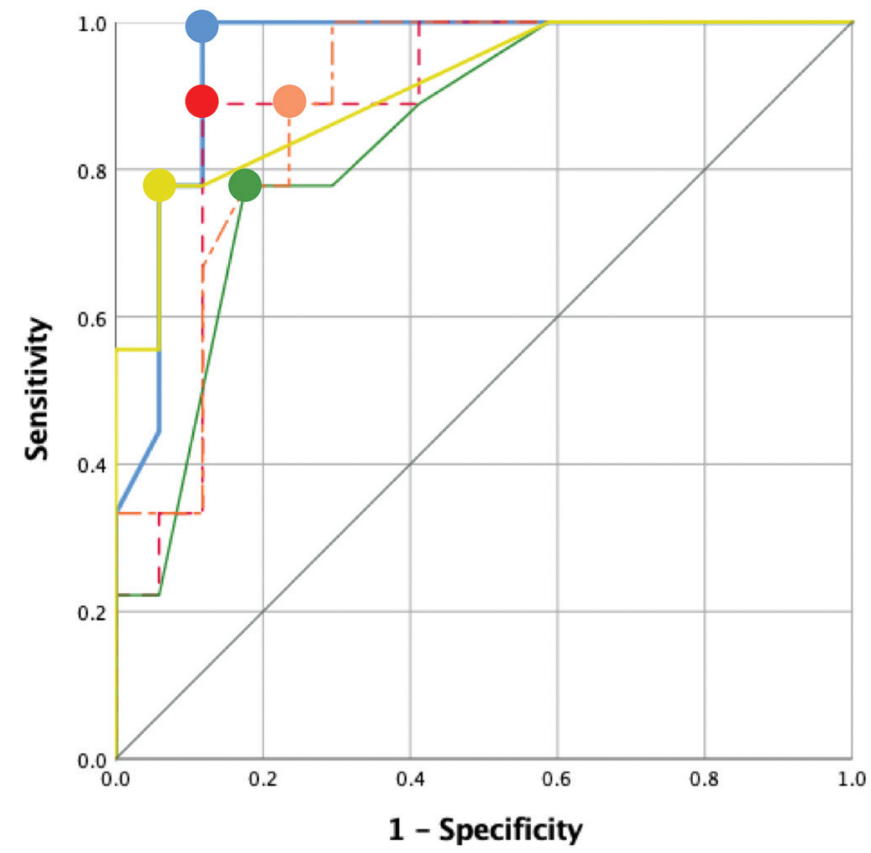

Diagonal segments are produced by ties.

FIG 1. ROC analysis to predict RCVS using objective reversibility measurements and RCVS-2 scores. Circles identify best coordinates (cutoffs) for each curve.
Maximal PC

- Mean PC

Maximal CD

- Mean CD

RCVS-2 Score

Reference Line

in affected arteries after the IA infusion of verapamil was accurate eliable in distinguishing RCVS from other intracranial arteriothe caliber of each vascular segment had an excelmarker of reversibility on RCVS.

Patients with typical RCVS symptoms who present with TCH have a well-known trigger and a mild evolution with angiographic changes that generally resolve in 12 weeks. ${ }^{4}$ However, the clinical presentation of RCVS is variable, and patients may present without $\mathrm{TCH}$ in up to $15 \%$ of cases. ${ }^{20}$ Patients without $\mathrm{TCH}$ may experience severe forms of RCVS, present with coma or confusion due to stroke or posterior reversible encephalopathy syndrome, or have fulminant RCVS. The clinical spectrum of RCVS varies among different populations, and the diagnosis of atypical cases can be challenging. ${ }^{21}$ Moreover, the classic "string of beads" appearance of vasoconstriction has been described in only $12 \%-81 \%$ of patients with RCVS. ${ }^{4}$

Previous reports have suggested the benefit of calcium channel blockers (nicardipine, verapamil, and nimodipine) and phosphodiesterase inhibitors (milrinone) in diagnosing and treating RCVS (On-line Table 3). ${ }^{11-18,22-24}$ Diagnosis entails the IA infusion of these drugs to determine the improvement in the caliber of the affected vascular segment. Other vasculopathies such as ICAD and PACNS usually do not improve after these challenges or have a milder response, perhaps suggesting some degree of overlap between these conditions. Ospel et $\mathrm{al}^{18}$ used verapamil in diagnosing RCVS by documenting the reversibility of vascular changes in 11 patients. Luminal narrowing was classified as mild $=<30 \%$ of normal caliber, moderate $=30 \%-$ $60 \%$ of normal caliber, and severe $=$

Table 3: Cutoffs, AUC, sensitivity, specificity, and positive and negative predictive values of different reversibility measurements

\begin{tabular}{|c|c|c|c|c|c|c|c|}
\hline Reversibility Measurement & Cutoff & AUC & $95 \% \mathrm{Cl}$ & Sen & Spe & PPV & NPV \\
\hline Maximal PC (\%) & $\geq 32$ & 0.951 & $0.87-1.00$ & 100 & 88.2 & 81.8 & 100 \\
\hline Mean PC (\%) & $\geq 14.4$ & 0.886 & $0.76-1.00$ & 88.9 & 88.2 & 80 & 93.8 \\
\hline Maximal CD (mm) & $\geq 0.45$ & 0.840 & $0.68-0.99$ & 77.8 & 82.4 & 70 & 87.5 \\
\hline Mean CD (mm) & $\geq 0.125$ & 0.882 & $0.75-1.00$ & 88.9 & 76.5 & 66.7 & 92.8 \\
\hline RCVS-2 score (points) & $\geq 5.0$ & 0.908 & $0.79-1.00$ & 77.8 & 94.1 & 87.5 & 88.9 \\
\hline
\end{tabular}

Note:-NPV indicates negative predictive value; PPV, positive predictive value; Sen, sensitivity; Spe, specificity. 


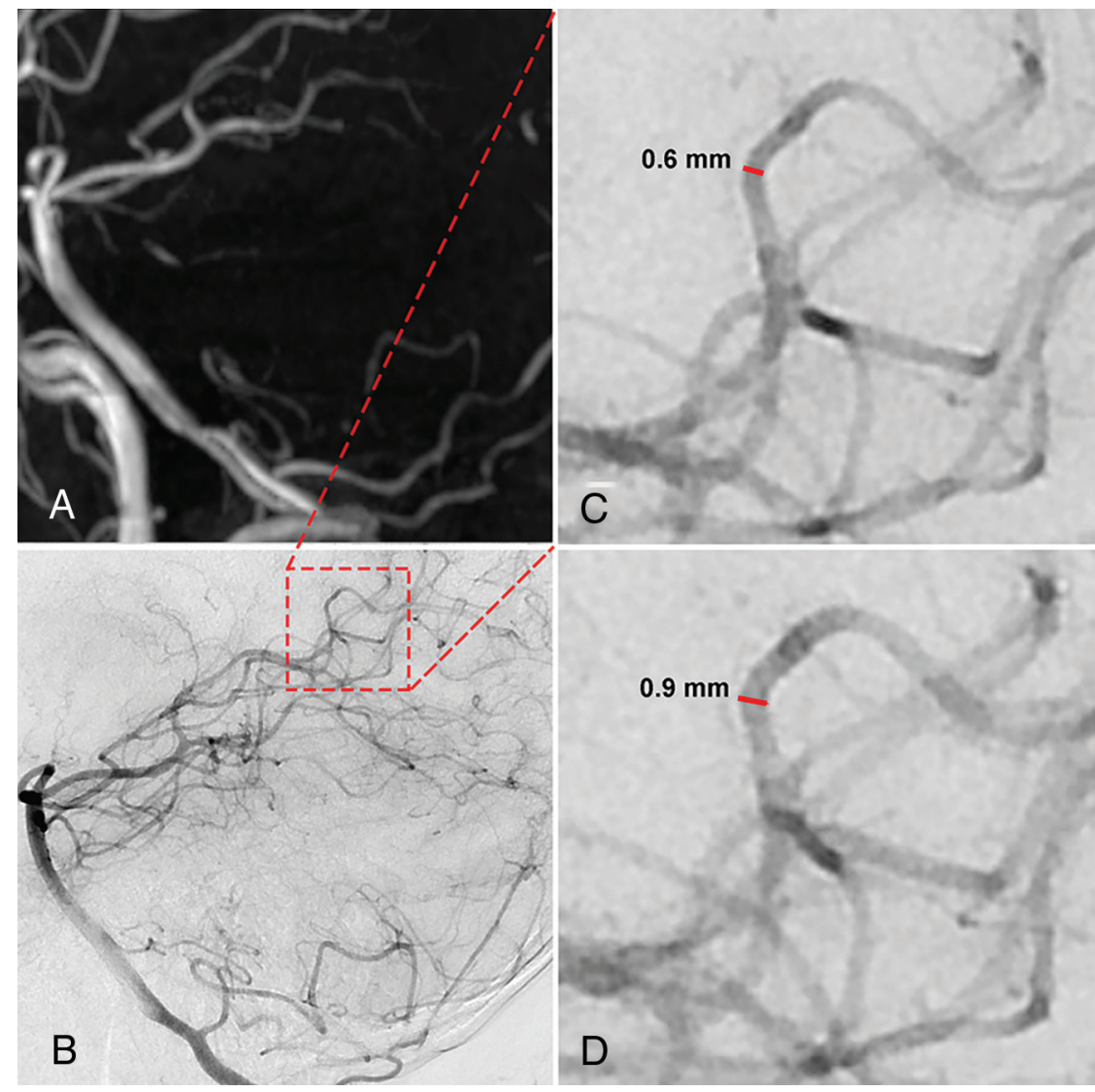

FIG 2. A, Contrast-enhanced MRA of a patient with atypical RCVS. The posterior cerebral artery branches appear unremarkable. $B$, Lateral angiogram with areas of segmental narrowing in the posterior circulation. $C$, Pre-verapamil infusion DSA shows the caliber of a P3 branch $=0.6 \mathrm{~mm}$ $D$, Post-verapamil infusion DSA shows a $0.3-\mathrm{mm} \mathrm{CD}(0.9-0.6 \mathrm{~mm}, 50 \% \mathrm{PC})$ in the $\mathrm{P} 3$ branch at the same level. These subtle changes in distal branches were not diagnosed in subjective assessments.

$>60 \%$ of normal caliber. We have objectively documented that a maximal proportion of change of $32 \%$ in the lumen diameter after the administration of IA verapamil had a sensitivity of $100 \%$ and a specificity of $82 \%$ in diagnosing RCVS. All the RCVS cases included in our series were confirmed as RCVS on follow-up using strict diagnostic criteria.

The sensitivity and specificity of DSA in diagnosing RCVS has not been assessed in blinded studies. ${ }^{4}$ However, the sensitivity of indirect methods of angiography such as CTA and/or MRA is about $70 \%$ compared with DSA. ${ }^{25}$ Furthermore, patients may have normal findings on the first DSA if performed early. Thus, subsequent angiograms may be required 1 week after the onset of symptoms to document changes. ${ }^{26}$ Our subjective assessment showed poor intra- and interobserver agreement when determining caliber changes in the middle and distal branches. In our cohort, these vascular regions are involved in approximately $89 \%$ and $72 \%$ of cases, respectively. Singhal et $\mathrm{al}^{8}$ also reported $92 \%$ and $86 \%$ of changes affecting the middle and distal branches, respectively. The accuracy of CTA/MRA in detecting mild changes in the distal branches is lower than that of DSA due to their inferior spatial resolution (Fig $2)^{2,27,28}$ The sensitivity of CTA and MRA in detecting small $(<3$ $\mathrm{mm}$ ) aneurysms is inferior to that of DSA. ${ }^{29}$ The accuracy of these noninvasive imaging modalities in determining $<1$-mm caliber changes in the middle and distal branches is insufficient compared with DSA. The objective DSA quantification of changes in the diameter of vascular segments after the administration of IA verapamil demonstrated high accuracy in detecting RCVS (Fig 3). Therefore, objective rather than subjective quantification of subtle changes in pre- and post-IA verapamil angiograms should be routinely performed to ascertain the correct diagnosis.

The role of DSA in RCVS has been criticized for its invasiveness, radiation exposure, use of contrast, and lack of scope for intervention. ${ }^{30}$ Moreover, the IA administration of vasoactive drugs has been questioned due to the risk of iatrogenic hypotension, reperfusion injury, and theoretic disruption of the blood-brain barrier. ${ }^{31}$ While most patients with RCVS have a good outcome, a considerable number of patients will experience a more fulminant course that results in permanent disability or death. This occurs most prominently in patients with atypical clinical presentations whose diagnosis and subsequent treatment are delayed. ${ }^{31}$ There is growing evidence that IA administration of vasoactive drugs can be done safely and that DSA may be therapeutic in addition to its valuable diagnostic capabilities. ${ }^{10,13}$ It is also possible that the verapamil-induced vasodilation shortens the course of the illness and lowers the chances of subsequent ischemic complications. We recommend DSA with IA verapamil challenge for patients with atypical RCVS presentations (without $\mathrm{TCH}$ or classical triggers), slow disease evolution, or an alternative diagnosis being entertained. DSA is particularly helpful if there is an intracranial lesion (ischemic or hemorrhagic) and normal indirect angiographic findings (CTA/MRA) in the setting of a suspected intracranial vasculopathy like RCVS.

This study is limited by the small number of patients. RCVS is a rare condition, and a more thorough assessment would require a prospective multicenter study. Another limitation is the intrinsic selection bias favoring recruitment of sicker patients. Every patient had abnormal imaging findings with evidence of an ischemic stroke and/or hemorrhage at presentation, but almost half did not have the typical TCH. Milder cases of RCVS with typical presentation were not referred for DSA. Therefore, the reversibility of vasoconstriction and the diagnostic accuracy of the IA verapamil challenge are yet to be proved in most cases of RCVS. An ideal statistical comparison between the 2 diagnostic tools became difficult due to few patients with atypical 


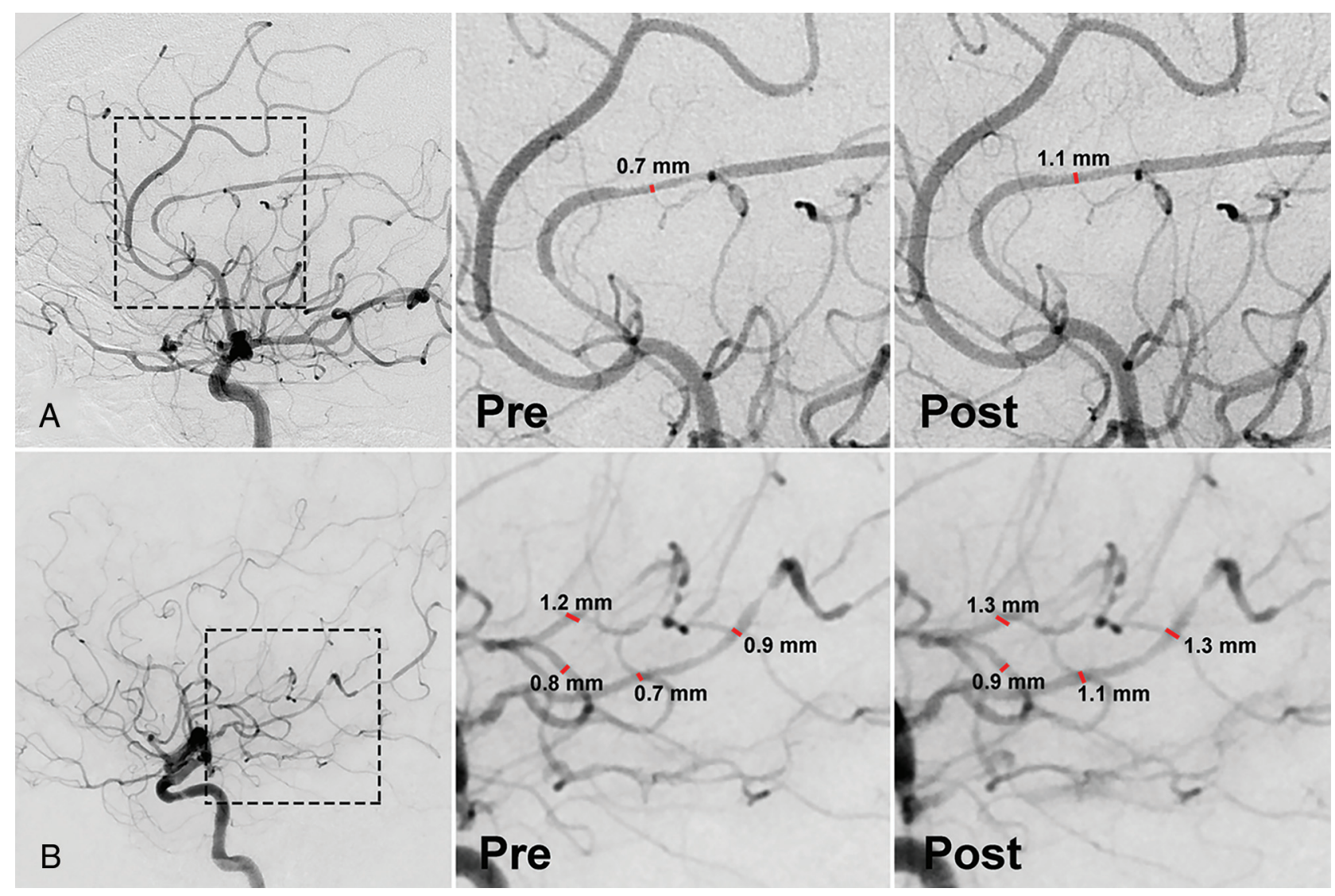

FIG 3. A, Patient with RCVS in the right anterior cerebral artery territory. B, Patient with RCVS in the right posterior cerebral artery territory. Note the classic string of beads pattern of the affected branches. The square delineates zoomed-in areas of the angiogram that were blindly analyzed by 2 readers. These measurements were later labeled as pre- and post-IA verapamil.

presentations of RCVS, even at a high-volume stroke center. The method used for objective vessel-caliber assessment in this study might seem laborious, but for a vascular neuroimaging-trained physician, it would take only a few additional minutes at the workstation. With the recent overwhelming advances in neuroradiology using artificial intelligence, ${ }^{32}$ an automated assessment tool might be feasible in the near future.

\section{CONCLUSIONS}

Objective quantification of the caliber of affected arterial segments on pre- and post- IA verapamil angiograms has a high diagnostic yield in patients with atypical RCVS. A maximal proportion of change $\geq 32 \%$ had the best performance as a diagnostic tool and was superior to both subjective assessment of reversibility and the clinical RCVS-2 score.

Data are available on reasonable request. Additional unpublished data will be made available by the corresponding author with an appropriate request.

Disclosures: Santiago Ortega-Gutierrez-UNRELATED: Consultancy: Stryker and Medtronic proctor; * Colin P. Derdeyn—UNRELATED: Consultancy: Penumbra, Genae, NoNo, Comments: Data and Safety Monitoring Boards for clinical trials*; Employment. University of lowa Hospitals and Clinics; Stock/Stock Options: Pulse Therapeutics. *Money paid to the institution.

\section{REFERENCES}

1. Calabrese LH, Dodick DW, Schwedt TJ, et al. Narrative review: reversible cerebral vasoconstriction syndromes. Ann Intern Med 2007;146:34-44 CrossRef Medline

2. Miller TR, Shivashankar R, Mossa-Basha M, et al. Reversible cerebral vasoconstriction syndrome, Part 2: diagnostic work-up, imaging evaluation, and differential diagnosis. AJNR Am J Neuroradiol 2015;36:1580-88 CrossRef Medline

3. Singhal AB, Hajj-Ali RA, Topcuoglu MA, et al. Reversible cerebral vasoconstriction syndromes: analysis of 139 cases. Arch Neurol 2011;68:1005-12 CrossRef Medline

4. Ducros A. Reversible cerebral vasoconstriction syndrome. Lancet Neurol 2012;11:906-17 CrossRef Medline

5. Ducros A, Boukobza M, Porcher R, et al. The clinical and radiological spectrum of reversible cerebral vasoconstriction syndrome: a prospective series of 67 patients. Brain 2007;130:3091-101 CrossRef Medline

6. Kadkhodayan Y, Alreshaid A, Moran CJ, et al. Primary angiitis of the central nervous system at conventional angiography. Radiology 2004;233:878-82 CrossRef Medline

7. Singhal AB, Topcuoglu MA. Glucocorticoid-associated worsening in reversible cerebral vasoconstriction syndrome. Neurology 2017;88:22836 CrossRef Medline

8. Singhal AB, Topcuoglu MA, Fok JW, et al. Reversible cerebral vasoconstriction syndromes and primary angiitis of the central nervous system: clinical, imaging, and angiographic comparison. Ann Neurol 2016;79:882-94 CrossRef Medline

9. Rocha EA, Topcuoglu MA, Silva GS, et al. RCVS2 score and diagnostic approach for reversible cerebral vasoconstriction syndrome. Neurology 2019;92:e639-47 CrossRef Medline 
10. Crockett MT, Di Loreto M, Philips TJ. Severe reversible cerebral vasoconstriction syndrome in a postpartum patient treated successfully with direct instillation of intra-arterial verapamil during cerebral angiography. J Vasc Interv Neurol 2017;9:43-44 Medline

11. Elstner M, Linn J, Muller-Schunk S, et al. Reversible cerebral vasoconstriction syndrome: a complicated clinical course treated with intra-arterial application of nimodipine. Cephalalgia 2009;29:67782 CrossRef Medline

12. Farid H, Tatum JK, Wong C, et al. Reversible cerebral vasoconstriction syndrome: treatment with combined intra-arterial verapamil infusion and intracranial angioplasty. AJNR Am J Neuroradiol 2011;32:E184-87 CrossRef Medline

13. French KF, Hoesch RE, Allred J, et al. Repetitive use of intra-arterial verapamil in the treatment of reversible cerebral vasoconstriction syndrome. J Clin Neurosci 2012;19:174-76 CrossRef Medline

14. Ioannidis I, Nasis N, Agianniotaki A, et al. Reversible cerebral vasoconstriction syndrome: treatment with multiple sessions of intra-arterial nimodipine and angioplasty. Interv Neuroradiol 2012;18:297302 CrossRef Medline

15. John S, Donnelly M, Uchino K. Catastrophic reversible cerebral vasoconstriction syndrome associated with serotonin syndrome. Headache 2013;53:1482-87 CrossRef Medline

16. Kass-Hout T, Kass-Hout $\mathrm{O}$, Sun $\mathrm{CH}$, et al. A novel approach to diagnose reversible cerebral vasoconstriction syndrome: a case series. J Stroke Cerebrovasc Dis 2015;24:e31-37 CrossRef Medline

17. Linn J, Fesl G, Ottomeyer C, et al. Intra-arterial application of nimodipine in reversible cerebral vasoconstriction syndrome: a diagnostic tool in select cases? Cephalalgia 2011;31:1074-81 CrossRef Medline

18. Ospel JM, Wright $\mathrm{CH}$, Jung $\mathrm{R}$, et al. Intra-arterial verapamil treatment in oral therapy-refractory reversible cerebral vasoconstriction syndrome. AJNR Am J Neuroradiol 2020;41:293-99 CrossRef Medline

19. Milburn JM, Moran CJ, Cross DT, et al. Increase in diameters of vasospastic intracranial arteries by intraarterial papaverine administration. J Neurosurg 1998;88:38-42 CrossRef Medline

20. Wolff V, Ducros A. Reversible cerebral vasoconstriction syndrome without typical thunderclap headache. Headache 2016;56:674-87 CrossRef Medline
21. Caria F, Zedde M, Gamba M, et al; Italian Project on Stroke at Young Age (IPSYS) Investigators. The clinical spectrum of reversible cerebral vasoconstriction syndrome: the Italian Project on Stroke at Young Age (IPSYS). Cephalalgia 2019;39:1267-76 CrossRef Medline

22. Al-Mufti F, Dodson V, Wajswol E, et al. Chemical angioplasty for medically refractory reversible cerebral vasoconstriction syndrome. Br J Neurosurg 2018;32:431-35 CrossRef Medline

23. Bouchard M, Verreault S, Gariepy JL, et al. Intra-arterial milrinone for reversible cerebral vasoconstriction syndrome. Headache 2009;49:14245 CrossRef Medline

24. Laneuville M, Ding J, Shamy M, et al. Intra-arterial milrinone may differentiate fulminant RCVS from vasculitis. Neurology 2017;89:109394 CrossRef Medline

25. Ducros A, Bousser MG. Reversible cerebral vasoconstriction syndrome. Pract Neurol 2009;9:256-67 CrossRef Medline

26. Ghia D, Cuganesan R, Cappelen-Smith C. Delayed angiographic changes in postpartum cerebral angiopathy. $J$ Clin Neurosci 2011;18:435-36 CrossRef Medline

27. Ducros A, Wolff $\mathrm{V}$. The typical thunderclap headache of reversible cerebral vasoconstriction syndrome and its various triggers. Headache 2016;56:657-73 CrossRef Medline

28. Hartung MP, Grist TM, François CJ. Magnetic resonance angiography: current status and future directions. J Cardiovasc Magn Reson 2011;13:19 CrossRef Medline

29. Turan N, Heider RA, Roy AK, et al. Current perspectives in imaging modalities for the assessment of unruptured intracranial aneurysms: a comparative analysis and review. World Neurosurg 2018;113:280-92 CrossRef Medline

30. Tan LH, Flower O. Reversible cerebral vasoconstriction syndrome: an important cause of acute severe headache. Emerg Med Int 2012;2012:303152 CrossRef Medline

31. Miller TR, Shivashankar R, Mossa-Basha M, et al. Reversible cerebral vasoconstriction syndrome, Part 1: epidemiology, pathogenesis, and clinical course. AJNR Am J Neuroradiol 2015;36:1392-99 CrossRef Medline

32. Hosny A, Parmar C, Quackenbush J, et al. Artificial intellience in radiology. Nat Rev Cancer 2018;18:500-10 CrossRef Medline 